\title{
Treatments on the Survival of Pinus canariensis Chr. Sm. Ex DC in Buch Planted Seedlings in Arid Zones (Herbivore Protectors-Fertilizers-Mulch- Hydrogels)
}

\author{
José Ramón Arévalo*
}

Departamento de Ecología, Universidad de La Laguna. La Laguna, 38206, Tenerife, Spain

\begin{abstract}
Long periods of deforestation in the southern part of Tenerife Island have led to a point-of-no-return for recovery of vegetation, which requires human intervention. Good plantation techniques could help regenerate woody plants.

A study was designed to provide information about the best plantation techniques for Pinus canariensis in the southern part of Tenerife, at the old pine forest location (precipitation $<250 \mathrm{~mm}$ and $12^{\circ} \mathrm{C}$ mean annual temperature). Two study sites were selected (Fasnia and Arico); in each site two plots of 5 ha were established. In total, 4 plots were located and in each plot, 32 subplots of 16 x 16 m were marked out. In each subplot, 16 Pinus canariensis seedlings (1 year old) were planted and subjected to different combinations of fertilizers, chemical herbivore preventers, mechanical herbivore preventers (using stone castle, hay protectors and plastic protectors), hydrogels and mulch, giving a total of 32 subplot combinations. I monitored the rate of pine seedling survival over three years. The results indicated that fertilization had a negative effect on survivorship of the pine seedlings. Stone castle protectors and hydrogels were also negatively associated with seedling survival. By contrast, plastic protectors showed the highest efficiency in aiding seedling survivorship, and they also represent the quickest option in terms of how long it takes to employ the device.
\end{abstract}

Given the soil and weather conditions of the study area, I would not recommend fertilization or hydrogels. Plastic protectors are recommended as herbivore protection, because they are easy to set up and offer better results.

Keywords: Plantation, restoration, fertilizers, hydrogels, herbivore repellents.

\section{INTRODUCTION}

The natural regeneration of the forest stand faces many difficulties in areas that have been subjected to long-term degradation and loss of soil. In these conditions, the only way to promote some tree regeneration in the area is to establish seedlings in a protected environment and later plant them where they will grow [1]. Successful establishment of plants for reforestation depends upon a wide range of interacting factors, including: climate, soil, competing species and post-plantation care [2]. The main objectives of a plantation are the optimization of seedling survival, and the growth and stability of the plant [3]. However, in some areas poor seedling survival rates are common. Seedling survival depends on the ability of the productive leaf to produce carbohydrates for the growth of the whole plant and on early extension of the root system to contact soil moisture reserves [4]. This is facilitated by good management of water inputs [5]. Even if planting is done in an appropriate season, the plant is cultivated in a suitable container, and with the correct species, there are other factors that may hamper the success of the plantation, such as livestock grazing, soil nutrient content and the genetic quality of the plant.

*Address correspondence to this author at the Departamento de Ecología, Universidad de La Laguna. La Laguna, 38206, Tenerife, Spain;

E-mail: jarevalo@ull.es
Plantation programs have been very common in the Canary Islands since the 1940s. In general, one of the main objectives of these plantations is to restore the Canarian pine (Pinus canariensis Chr. Sm. Ex DC in Buch) forest that has been heavily disturbed and eliminated over the last five centuries, after the European colonization of the Canary Islands [6] and subsequent reforestation with exotic species [7]. In recent years, the authorities have re-considered the usefulness of plantations, moving away from the idea of using them exclusively as exploitable natural resources towards a management practice that will restore the native pine forest. Remaining areas of potential $P$. canariensis forest have been planted with poor results [8]. The underlying reasons for these poor results (in some cases 90$100 \%$ seedling mortality) are weather conditions, nutrient soil conditions or herbivory [9].

The main objective of this study is to analyze the effects of fertilization, hydrogels, mulch and grazing protectors on the survival of Pinus canariensis seedling plantations as traditional methods that are considered to be factors that increase seedling survivorship in inappropriate environmental conditions. I combined all these treatments in order to determine which treatment best ensures the survival of the plants over a number of years in an area with unfavourable weather conditions. The hypotheses to test were: fertilizers and hydrogels will increase the survival rate 
of plants, and type of grazing protector will not affect the survival rate of plants.

These studies provide valuable information for the development of plantation planning. A more complete understanding of these processes will help us to develop plantation systems that will provide a more successful environment for seedling establishment.

\section{MATERIAL AND METHODS}

\section{Study Site}

The study was carried out on the leeward side of the island, in the Corona Forestal Natural Park. The park comprises $46,636 \mathrm{ha}$, and $25 \%$ has been reforested with Pinus canariensis, with minor plantings of Pinus radiata. In these areas, most reforestations were carried out between
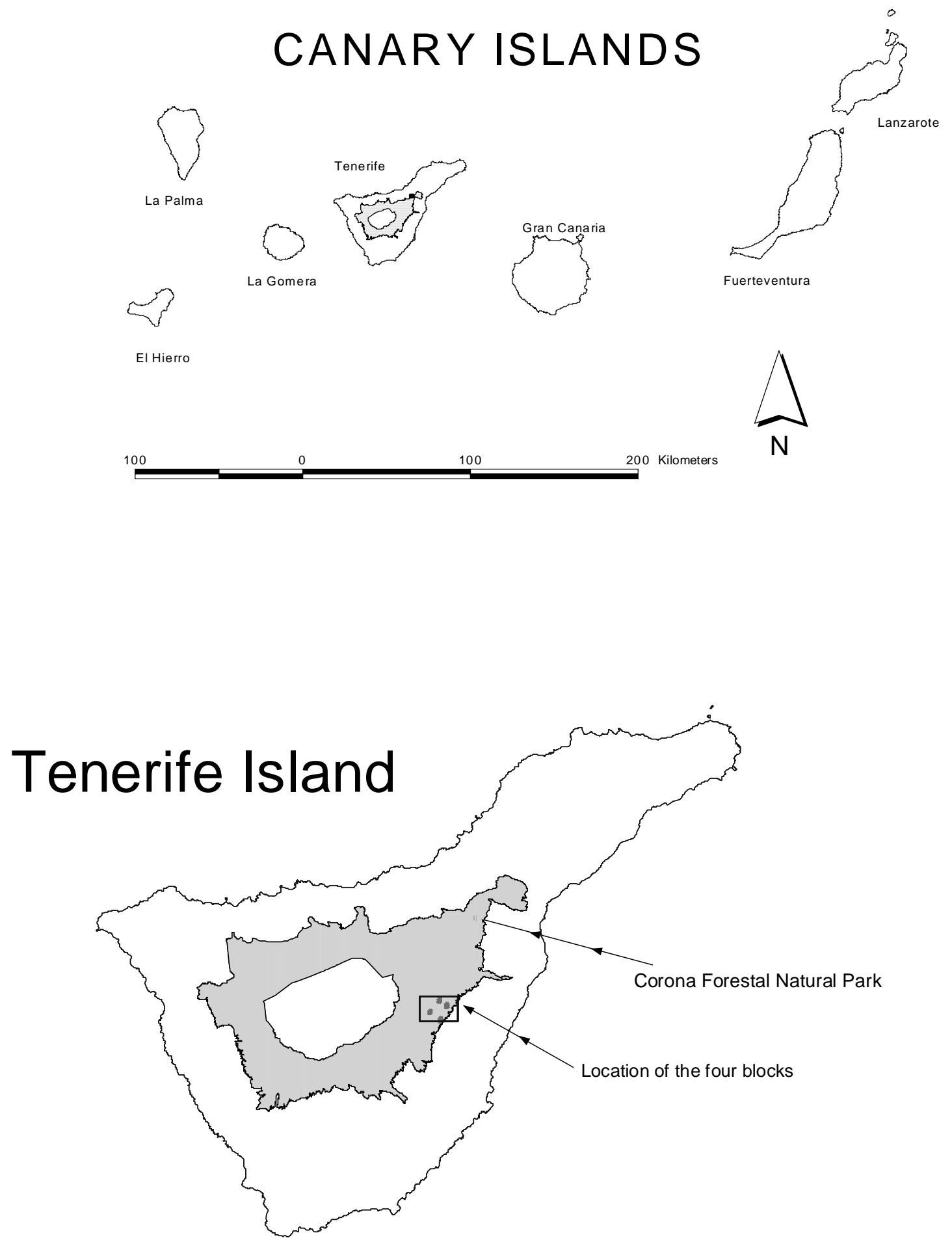

Fig. (1). Map of the Canary Islands, indicating Corona Forestal Natural Park on tenerife. The location of the four blocks in Tenerife is indicated in a quadrant with dots as location of the plots. 
1930 and 1940 [10]. The sites selected for our study were planted between 1948 and 1952. Two sites were selected (Fasnia and Arico) and in each site two different plots of 5 ha were fixed (Fig. 1). I considered that the four plots could be taken as four replicates as long as they were incorporated in an area with similar potential vegetation, soil and minor variations in climatic conditions. These areas had had poor regeneration results in previous Pinus canariensis plantation attempts, with mortality in some case reaching 95-100\%.

The Fasnia site is located between 1395 and $1750 \mathrm{~m}$ asl, with a slope of $17 \%$. The Arico site is located between 1315 and $1800 \mathrm{~m}$ asl, with a slope of about $20 \%$. The understory vegetation of these sites is dominated by Chamaecytisus proliferus, Echium plantigineum and Micromeria spp. (species typically found in degraded areas). Average rainfall in the two sites is $<300 \mathrm{~mm}$ per year and mean temperature values are $15^{\circ} \mathrm{C}$ [11]. The climatic characteristics of the area are classified as desertic, with low precipitation and cold temperatures $\left(<15^{\circ}\right.$ annual mean [12]). Soils are high in rocks $(30-50 \%)$ and are classified as litosols and brown soils (Cambisols and Leptosols) [13].

\section{Experimental Design}

Fertilized treatments and grazing protectors were combined, which resulted in a total of 32 different treatments per plot. The treatments were:

1. NPK oscomocot fertilizer pellets (14-14-14 NPK, 30 $\mathrm{g} /$ for each plant hole, approximately),

2. $30 \mathrm{~g}$ hydrogel in each hole (crosslinked polyacrylamides, which are swollen by water and are characterized by the presence of a main polymer 'backbone' with attached polar groups. These polymers form aqueous gels which are able to absorb and store up to 400 times their own weight of water, build an additional water reservoir for the plant-soilsystem and therefore, reduce water stress for the trees),

3. use of mulch, a hay carpet of $30 \times 30 \mathrm{~cm}$ and $2 \mathrm{~cm}$ thick that may diminish soil evaporation.

The herbivorous grazing protectors were

1. esparto carpet $(\mathrm{PE})$;

2. $\quad 40-\mathrm{cm}$ tall plastic herbivore preventers (PP),

3. Herbivore prevention by stone castle (PG),

4. herbivore repellent PR (sprayed ammonium soap and fatty acid base: Hinder repellent trademark).

In each of the four plots, 32 subplots of $16 \times 16 \mathrm{~m}$ were designated (with a distance of $10 \mathrm{~m}$ between each plot), and a different combination of treatments was used in each one (Table 1). The treatments of the subplots were assigned randomly.

In each subplot, 16 pines seedlings (10-12 months postgermination from a greenhouse) were planted. They were originally established in a "super-leach M-32" container, in which the substrate composition was $1: 1$ vermiculite:turba. Containers have important effects on the field performance of plants [14] but previous experience has shown the use of this type of container to be appropriate (Arévalo, unpublished). During the nursery period pine seedlings were regularly watered and fertilized following standard nursery protocols (the fertilizer was a typical 20-10-20 NPK providing a total for the greenhouse period of $100 \mathrm{mgN}$ ).

Table 1. 32 Subplots Combination of the Treatments and Herbivorous Grazing Protection Established in Each Plots

\begin{tabular}{|c|l|l|l|}
\hline 1. & GS-MS-PP-FS & 17. & GN-MS-PP-FS \\
\hline 2. & GS-MS-PP-FN & 18. & GN-MS-PP-FN \\
\hline 3. & GS-MS-PE-FS & 19. & GN-MS-PE-FS \\
\hline 4. & GS-MS-PE-FN & 20. & GN-MS-PE-FN \\
\hline 5. & GS-MS-PR-FS & 21. & GN-MS-PR-FS \\
\hline 6. & GS-MS-PR-FN & 22. & GN-MS-PR-FN \\
\hline 7. & GS-MS-PG-FS & 23. & GN-MS-PG-FS \\
\hline 8. & GS-MS-PG-FN & 24. & GN-MS-PG-FN \\
\hline 9. & GS-MN-PP-FS & 25. & GN-MN-PP-FS \\
\hline 10. & GS-MN-PP-FN & 26. & GN-MN-PP-FN \\
\hline 11. & GS-MN-PE-FS & 27. & GN-MN-PE-FS \\
\hline 12. & GS-MN-PE-FN & 28. & GN-MN-PE-FN \\
\hline 13. & GS-MN-PR-FS & 29. & GN-MN-PR-FS \\
\hline 14. & GS-MN-PR-FN & 30. & GN-MN-PR-FN \\
\hline 15. & GS-MN-PG-FS & 31. & GN-MN-PG-FS \\
\hline 16. & GS-MN-PG-FN & 32. & GN-MN-PG-FN \\
\hline
\end{tabular}

Vertical protection: Plastic (PP), Esparto (PE), Stone castle (PG). Herbivore protection (PR). Fertilizers: Applied (FS), Non applied (FN); Hydrogels resins: Applied (GS), non applied (GN); Mulch applied MS and mulch non applied MN.

A hole of 40x40x40 cm was made by hand for each pine seedling, and 20-30 liters of water were added to the hole before planting. Pinus canariensis plantations were carried out in January-February 2000, and the survivorship of plants were monitored during the following three years at different periods within each year: April (2 months after plantation), May (3), September (7), October (8), December 2000(10), April 2001(14), April 2002(26) and April 2003.

\section{Statistical Analysis}

A model was created to predict the percentage of survivorship of pine seedlings (dependent variable) in relation to all treatments, represented in the analysis as dummy independent variables: fertilizer, hydrogels, mulch and herbivore protector (plastic, esparto, stone castle and herbivore repellent) using a forward stepwise multiple nominal regression (using a $P<0.05$ to include variables in the model)

I compared survivorship values between subplots with different vertical protectors (plastic, esparto, stone cattle, repellent) with a one-way ANOVA (for a $\mathrm{p}<0.05$ ) and mean survival values for fertilized versus non-fertilized plots with a Student- $t$ test. I used the Shapiro-Wilk test to examine the normality of the data and the Fmax to examine the homoscedasticity of the data (using a $\mathrm{p}<0.05$ ). Statistical methods followed Zar [15] and were implemented using SPSS [16]. 


\section{RESULTS}

A total of 2048 plants, distributed over four plots (128 subplots), were monitored or three years. Temporal monitoring of survival rate as a function of treatment in the different subplots revealed similar patterns throughout the study in the four plots (mean values were calculated across the four plots with the same treatment in each site; Fig. 2). The treatments were indicated in the abscissa and were ordinate from highest to lowest survivorship in the last sampling. The pattern of survivorship between the treatments remained very similar during all sampling periods.

Three months after plantation, mortality reached $2-3 \%$ on average, denoting a high \% of seedling survival. However, the percentage of survival decreased considerably one year after plantation. Likewise, after the first year and until the end of the study, a consistent pattern emerged: non-fertilized plots and plots without hydrogels, in general, showed the highest percentages of survivors. In addition, plots that included fertilization tablets and gels had the lowest rates of survivorship in general (Fig. 2).

Stepwise regression revealed a significant model $\left(\mathrm{F}_{2,125}=10.526, P<0.001\right)$ with only the variables fertilization $(\beta=-1.498, P<0.001)$ and castle stone $(\beta=-0.906, P<0.05)$ retained as significant, and both of them acted as inverse predictors of survivorship. The model indicated the negative effect of fertilization and castle stone on survivorship of the plants (although the effect of the second variable was not as strong as that of the first one).

Based on these results, I compared the rate of survivorship of all fertilized subplots with non-fertilized subplots (regardless of the other treatments applied or the plot). Non fertilized plots had higher survivorship than fertilized plots $(20.5 \%$ mean survivorship in none fertilized vs $11.1 \%$ in fertilized, $\mathrm{t}_{125}=-3.999, P<0.001$; Fig. 3a).

Moreover, I compared the rate of survivorship between different grazing protectors. The results of the ANOVA revealed no significant differences $\left(\mathrm{F}_{3,124}=1.168, P>0.05\right)$ among types of protectors (plastic $=19.12 \%$, esparto $=$ $16.00 \%$, repellent $=16.43 \%$ and stone castle $=11.5 \%$; Fig. 3b).

\section{DISCUSSION}

Planting Pinus canariensis seedlings is usually more effective than seeding, although more expensive. Planting is a crucial investment made in silviculture [1], although it should also be considered for restoration programs. Plantations in our study area have offered poorer results than in other studies due, in part, to low rain fall during the years of plantation (25 and $125 \mathrm{~mm}$ in 2000-2001 measured with our own pluviometers in the area). These observations do not justify the amount of money invested in the process of natural stand restoration. Hence, under these circumstances,
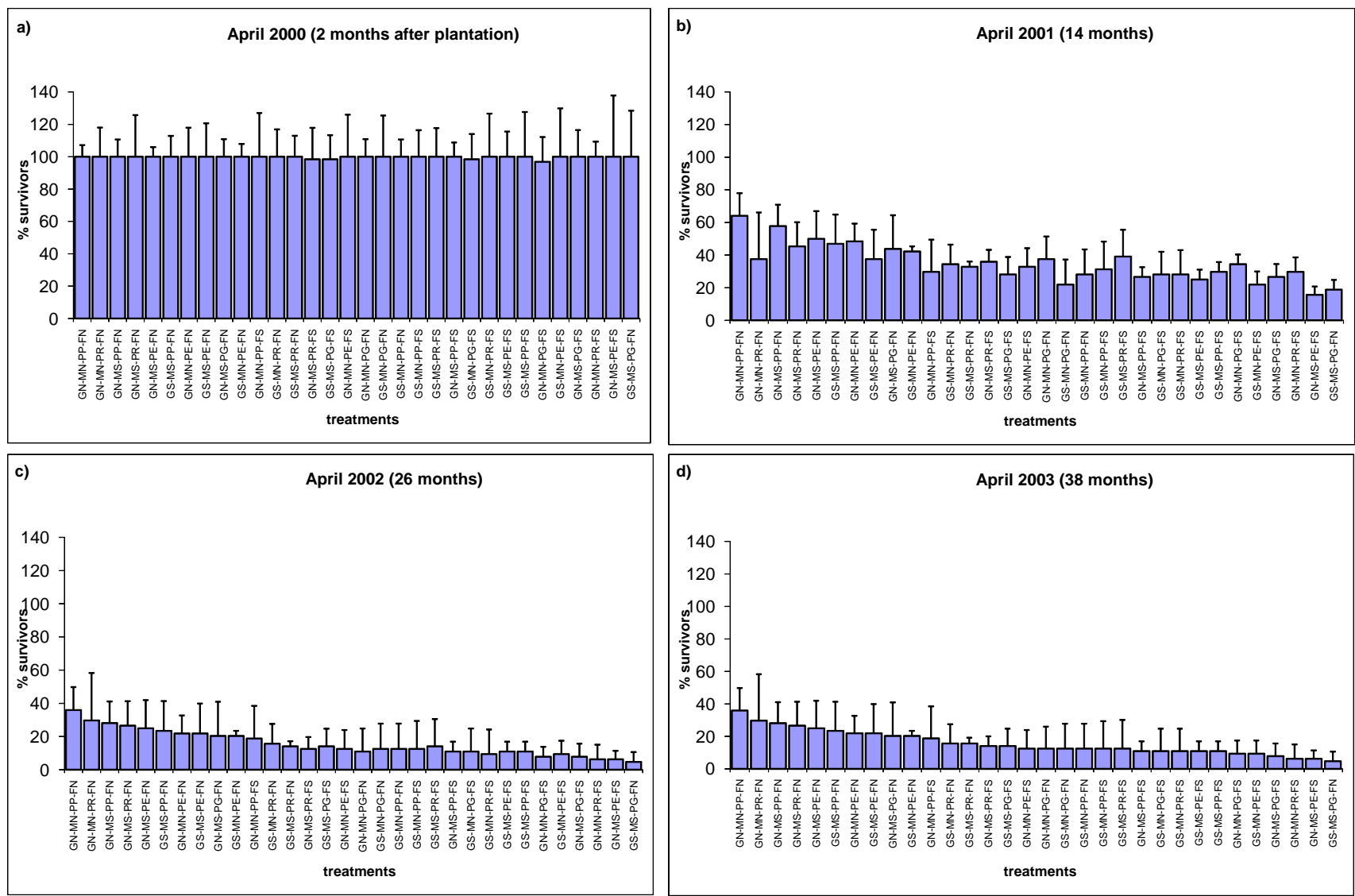

Fig. (2). Survivorship percentage average of the different treatments along the time (in columns and standard deviation in bars). Codes for combination of treatments are explained in Table $\mathbf{1 .}$ 

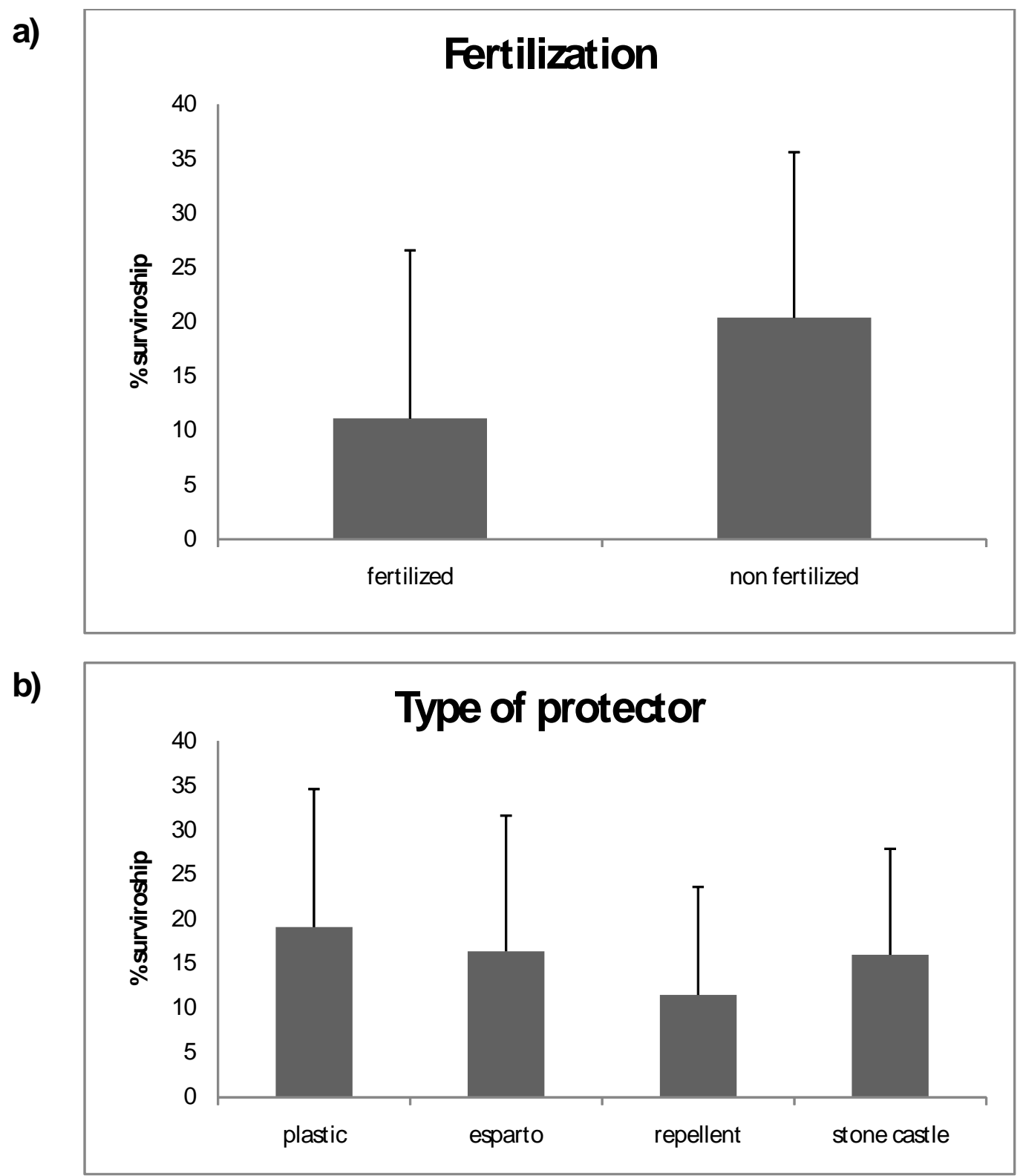

Fig. (3). (a) Mean values and standard deviation of percentage of survivorship for the 64 subplots fertilized vs non fertilized; (b) Mean values and standard deviation of percentage of survivorship in the 32 plots of each type of protector.

it was necessary to determine the best plantation techniques in these arid zones to increase planted pine survivorship.

Although mortality may be due to inappropriate nursery techniques [17], genetic factors [18], incorrect planting methods [3], or unsuitable containers for the production of plants [14], appropriate techniques and genetic varieties are available for Pinus canariensis. Nevertheless survivorship was still very low in the Tenerife plantations.

In the present study, the results of pine seedling survival refute the original hypothesis as the different fertilization techniques tested showed a low \% of pine survival (Fig. 2). The fertilization tablets used in this experiment resulted in increased mortality during the first two years. I tested several methods based on plant protection and fertilization to increase the survival rate of the plants, and some of the treatment results directly refuted my hypothesis, showing an increase in mortality due to the use of fertilizers and gels. One possible explanation could be related to the quantity of precipitation and the average temperature during the years after plantation. However, precipitation and temperature remained in line with average levels during the three years study lasted (200 $\mathrm{mmy}^{-1}$ and $15^{\circ} \mathrm{C}$ mean annual). Tthe main reasons for these disappointing results were probably related to low soil quality at the study sites. The study area soils suffer from considerable eolic and hydric erosion, high levels of degradation as a result of salinization and poor nutrient content [13]. The plots face south and sea spray can often be observed ascending into the plantation area. Rainfall is characterized by isolated heavy rains, liberating nutrients from the fertilization tablets sporadically instead of slowly and continuously as in greenhouses or nurseries, where watering is continuous and constant. The effect of sea spray is increased by herbivore protectors, because they capture 
more of this salty water by condensation (to a particularly high degree in the case of the plastic ones). Conductivity over $20,000 \mu \mathrm{scm}^{-1}$ has been observed in the rain water in some areas of the interior of the island [19]. Negative effects of sea spray on vegetation have been extensively analyzed [20-23]. Meteorological conditions are particular to this specific area of the island, with much lower rainfall than other south-facing areas of the island at the same altitude [11]. All these factors taken together influence the salinity of the soil and, consequently, the plant mortality rate.

The regression model retained stone castle as a significant variable related negatively to survivorship. As for the rest of the protectors, the plastic ones offered the best results, and they are the easiest to locate, thus enabling the work to be carried out more quickly, a very valuable characteristic in this type of forestry activity [24].

Standardized methods of herbivore protection, fertilization and techniques for maintaining humidity of the soils were applied in our experiments. The specific soil and weather conditions in our study area lead us not to recommend the use of fertilization or hydrogels, whereas plastic herbivore protectors are recommended because they are easy to locate and offer the best results. Using our recommendations, the survivorship rate after three years may increase from $20-30 \%$, making the plantation socially and economically feasible.

\section{ACKNOWLEDGMENTS}

I would like to thank Island Council (Cabildo) of Tenerife (Sección de Montes) for offering the funding and the procedures for the design of the experiment, especially initial data relating to the different treatments. I thank José Zoilo Hernández, Esther Morera and Beatriz Mora for their help with the field work. I am grateful to Dr. Jerry Husak for the time he dedicated to editing and making comments on this manuscript, and to Heather Adams for translating it into English.

\section{REFERENCES}

[1] Smith DM, Larson BC, Kelty MJ, Ashton PM. The practice of silviculture. Applied forest ecology. $9^{\text {th }}$ ed. New York: John Wiley \& Sons, Inc 1997.

[2] Luis VC, Peters J, González-Rodríguez AM, Jiménez MS, Morales D. Testing nursery plant quality of Canary Island pine seedlings grown under different cultivation methods. Phyton 2004; 44: 23144.

[3] Long AJ. In: Durya ML, Dougherty PM, Eds. Forest Regeneration Manual. Dordrecht: Kluwer Academic Publishers 1991; pp. 30320.

[4] Schult RC, Thompson JR. Effect of density control and undercutting on root morphology of $1+0$ barefoot hardwood seedlings: five year field performance of root-graded stock in the central USA. New Forests 1997; 13: 301-14.
[5] Specht A, Harvey-Jones J. Improving water delivery to the roots of recently transplanted seedling trees: the use of hydrogels to reduce leaf loss and hasten root establishment. Proceedings of the Conference: Managing and Growing trees. Queensland Government 1998; pp. 117-30.

[6] Parsons JJ. Human influence in the pine and laurel forest of the Canary Islands. Geogr Rev 191; 71: 253-71.

[7] Arévalo JR, Fernández-Palacios JM. From pine plantations to natural stands: Ecological restoration of a Pinus canariensis Sweet, ex Spreng forest. Plant Ecol 2005; 181: 217-26.

[8] Luis VC, Jiménez MS, Gil P, Morales D. Influencia de los factores ambientales en la mortalidad de plántulas de Pinus canariensis en condiciones naturales. Actas del III congreso forestal español, Granada 2001; pp. 361-72.

[9] Gómez-Aparicio L, Zamora R, Gómez JM. Regeneration status of the endangered Acer opalus subsp. granatense throughout its geographical distribution in thelberian peninsula. Biol Conserv 2005; 121: 195-206.

[10] del Arco MJ, Pérez de Paz PL, Salas M, Wildpret W. Atlas Cartográfico de los Pinares Canarios. II Tenerife. Viceconsejería de Medio Ambiente. Santa Cruz de Tenerife 1992.

[11] Diaz-Diaz R, Garcia-Hernandez JE, Loague K. Leaching potentials of four pesticides used for bananas in the Canary Islands. J Environ Qual 1998; 27: 562-72.

[12] Marzol V. In: Morales G, Pérez G, Eds. Gran Atlas Temático de Canarias. Editorial Insular Canaria, Santa Cruz de Tenerife 2000; pp. 87-106.

[13] Rodríguez A, Mora JL. In: Morales G, Pérez G, Eds. Gran Atlas Temático de Canarias. Editorial Insular Canaria, Santa Cruz de Tenerife 2000; pp. 107-20.

[14] Ortega U, Majada J, Mena-Petite A, et al. Field performance of Pinus radiata D. Don produced in nursery with different types of containers. New Forests 2006; 31: 97-112.

[15] Zar JH. Biostatistical analysis. $2^{\text {nd }}$ ed. Englewood Cliffs, NJ: Prentice Hall 1984.

[16] SPSS. SPSS/PC+ V.6.0. Base manual. Chicago: IL, SPSS Inc 1997.

[17] Mason EG. Causes of juvenile instability of Pinus radiata in New Zealand. N Z J For Sci 1985; 15: 236-80.

[18] Coutts MP, Nielsen CN, Nicoll BC. The development of symmetry, rigidity and anchorage in the structural root system of conifers. Plant Soil 1999; 217: 1-15.

[19] Aboal JR. Los flujos netos hidrológicos y químicos asociados de un bosque de laurisilva en Tenerife. Ph.D. Thesis. Universidad de La Laguna, La Laguna 1998.

[20] Nicolotti G, Rettori A, Paoletti E, Gullino ML. Morphological and physiological damage by surfactant-polluted seaspray on Pinus pinea and Pinus halepensis. Environ Monit Assess 2005; 105: 17591.

[21] Rettori A, Paoletti E, Nicolotti G, Gullino ML. Ecophysiological responses of Mediterranean pines to simulated sea aerosol polluted with an anionic surfactant: prospects for biomonitoring. Ann For Sci 2005; 62: 351-60.

[22] El Ayeb N, Henchi B, Garrec JP, Rejeb MN. Effects of polluted sea-spray on leaves of Acacia cyanophylla Lindl. and Eucalyptus gomphocephala Dc. in Tunisian coast. Ann For Sci 2004; 61: 28391.

[23] Richard B, Grieu P, Badot PM, Garrec JP. Influence of marine salts on the localization and accumulation of surfactant in the needles of Pinus halepensis Mill. Annales Des Sciences Forestieres 1996; 53: 921-30.

[24] Cubbage FW, Gunter JE, Olson JT. In: Durya ML, Dougherty PM. Eds. Forest Regeneration Manual. Dordrecht: Kluwer Academic Publishers 1991; pp. 9-31. 